\title{
Prevalence and clinical significance of pleural effusion in patients with acute pulmonary embolism: a retrospective study
}

\author{
Jiarui Zhang", Haixia Zhou", Adila Aili, Maoyun Wang, Yongchun Shen, Qun Yi \\ Department of Respiratory and Critical Care Medicine, West China Hospital of Sichuan University, Chengdu, China \\ Contributions: (I) Conception and design: Y Shen, Q Yi; (II) Administrative support: Q Yi; (III) Provision of study materials or patients: J Zhang, H \\ Zhou; (IV) Collection and assembly of data: A Aili, M Wang; (V) Data analysis and interpretation: J Zhang, H Zhou; (VI) Manuscript writing: All \\ authors; (VII) Final approval of manuscript: All authors. \\ \#These authors contributed equally to this work. \\ Correspondence to: Yongchun Shen, MD, Qun Yi, MD. Department of Respiratory and Critical Care Medicine, West China Hospital of Sichuan \\ University, Chengdu, China. Email: shen_yongchun@126.com; yiqun925@126.com.
}

\begin{abstract}
Background: Pleural effusion is observed in a subset of patients with acute pulmonary embolism (APE) and may be linked to clinical outcome, but findings from previous studies have been inconsistent. This study aimed to investigate the prevalence and clinical significance of pleural effusion in Chinese patients with APE. Methods: Clinical data from hospitalized patients with APE were retrospectively collected and the prevalence of pleural effusion was determined. The relationship between the presence of pleural effusion and clinical outcome of APE was analyzed by Cox proportional hazards regression and Kaplan-Meier survival analysis.
\end{abstract}

Results: The study enrolled 635 patients with APE. The prevalence of pleural effusion was $57.01 \%$ (362/635). Patients with pleural effusion had significantly higher in-hospital mortality (9.9\% vs. 4.8\%, $\mathrm{P}<0.05)$ and longer length of hospital stay (LOS) (19.99 vs. 15.31 days, $\mathrm{P}<0.05)$ than whose without pleural effusion. However, pleural effusion was not an independent risk factor for in-hospital mortality in patients with APE by multivariate Cox proportional hazards regression analysis [hazard ratio $(\mathrm{HR})=1.70,95 \%$ confidence interval (CI): 0.73-3.92, $\mathrm{P}=0.216$ ] and Kaplan-Meier survival analysis $(\mathrm{P}=0.174)$.

Conclusions: Pleural effusion is a frequent occurrence in patients with APE and therefore merits greater attention from clinicians; however, it is not an independent risk factor for in-hospital mortality.

Keywords: Acute pulmonary embolism (APE); pleural effusion; mortality

Submitted Jul 30, 2020. Accepted for publication Nov 18, 2020.

doi: $10.21037 /$ jtd-20-2552

View this article at: http://dx.doi.org/10.21037/jtd-20-2552

\section{Introduction}

Acute pulmonary embolism (APE) is a disease characterized by occlusion of one or more pulmonary arteries by a thrombus, and is a frequent reason for visits to the emergency room and hospital admission $(1,2)$. APE is a common cause of morbidity and mortality worldwide: In the past decade in Denmark, the annual prevalence increased from 45 to 83 per 100,000, and the prevalence in Sweden was reported as 60 per 100,000 per year $(3,4)$. In Australia in 2007, there were 320 deaths due to APE, corresponding to a mortality rate of 1.73 per 100,000 per year (5). In the
United States, APE accounts for 100,000-180,000 deaths per year (1). Although the mortality rate of APE has been declining in recent years because of progress in standard anticoagulant and thrombolytic therapies (6), it remains a significant public health concern. Mortality rates can be difficult to estimate because up to $25 \%$ of cases present as sudden death, while the rate ranges from $5 \%$ to $30 \%$ within the first 30 days of hospitalization (7). Timely identification of risk factors for mortality in APE patients can inform treatment decisions and improve prognosis.

Pleural effusion is commonly observed in patients with 
APE, with a prevalence of $32 \%$ and $47 \%$ based on chest $\mathrm{X}$-ray and chest computed tomography (CT), respectively (8). In contrast, the prevalence of pleural effusion was just $19.9 \%$ in 1,220 patients with PE (9). Pleural effusion has been linked to the severity and prognosis of APE, but the findings have been inconsistent. A study from Korea found that pleural effusion did not predict short-term outcome or length of hospital stay (LOS) in patients with APE (10), whereas investigations conducted in China and Turkey showed that pleural effusion in patients with APE was significantly correlated with higher mortality and was a potential independent risk factor of poor clinical outcome $(11,12)$. Thus, the clinical significance of pleural effusion in patients with APE remains unclear. To address this issue, the present study investigated the prevalence of pleural effusion and its impact on the outcome of Chinese patients with APE. We present the following article in accordance with the STROBE reporting checklist (available at http:// dx.doi.org/10.21037/jtd-20-2552).

\section{Methods}

\section{Study design and patients}

This retrospective, single-center cohort study was conducted at West China Hospital of Sichuan University, China, and enrolled patients aged $\geq 18$ years with APE diagnosed by CT pulmonary angiography (CTPA) between January 2015 and April 2019. The severity of APE was evaluated with the simplified PE severity index $(13,14)$. The presence of pleural effusion was determined based on CTPA findings by 2 experienced radiologists who were blinded to the medical history of the patients. Additionally, 2 pulmonary physicians determined the cause of pleural effusion by checking patients' medical records. There are many types of pleural effusion including parapneumonic, heart failureassociated, malignant, and tuberculous types $(15,16)$; these cases were excluded from the study. Parapneumonic pleural effusion results from pneumonia or lung infection and declines as the infection improves. Malignant pleural effusion is defined by the presence of malignant cells in the effusion or biopsy specimens. Tuberculous pleural effusion refers to any effusion secondary to Mycobacterium tuberculosis infection of pleura. Heart failure-associated pleural effusion is diagnosed when there is a medical history of heart failure and symptoms are relieved by diuretic therapy (16). The study was conducted in accordance with the Declaration of Helsinki (as revised in 2013). The study was approved by the Institutional Review Board of West China Hospital of Sichuan University (WCH 2017-351). The requirement for written, informed consent was waived because of its retrospective nature.

\section{Data collection}

All patients were followed up until discharge from the hospital, and their information was collected by reviewing medical records. Demographic characteristics, clinical presentation, comorbidities, laboratory and radiographic findings, and clinical outcome were recorded. Demographic data included age, sex, body mass index (BMI), and smoking history. Clinical presentation included initial vital signs, dyspnea, pleuritic chest pain, hemoptysis, syncope, fever, and leg pain or swelling. Predisposing or comorbid conditions included immobilization, trauma, cancer, stroke, chronic pulmonary disease (chronic obstructive pulmonary disease, asthma, bronchiectasis, idiopathic pulmonary fibrosis, pneumoconiosis, and tuberculosisdestroyed lung), pulmonary tuberculosis, and congestive heart failure. Laboratory findings included $\mathrm{N}$-terminal pro-B-type natriuretic peptide (NT-pro BNP), troponin T, creatine kinase-MB (CK-MB), white blood cell (WBC), and blood platelet (PLT) count. Radiologic findings included the location of pulmonary emboli detected by CTPA, deep vein thrombosis detected by ultrasonography, right ventricle dilation, and pulmonary infarction (defined as the appearance of peripheral consolidation secondary to PE detected by CT). Clinical outcomes were all-cause in-hospital mortality, rate of respiratory failure, tracheal intubation, mechanical ventilation, systemic thrombolysis, hospital bleeding, and LOS.

\section{Statistical analysis}

As none of the analyses were predefined based on previous reports they were considered as post hoc analyses. Categorical variables are presented as number count with a percentage value, and continuous variables are expressed as mean \pm standard deviation or median and interquartile range. The independent Student's $t$-test was used to assess differences between continuous variables and the MannWhitney $U$ test was used for data that were not normally distributed. The chi-squared test was used to analyze categorical variables. Clinical characteristics and laboratory and radiologic findings were compared between patients with and those without pleural effusion as well as between 


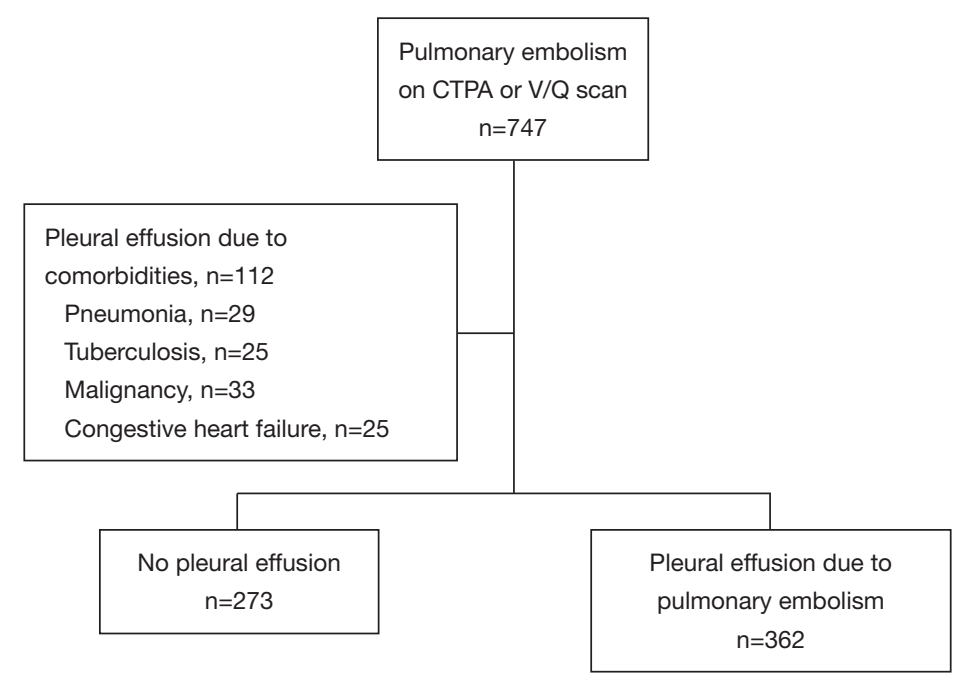

Figure 1 Flow diagram of the study protocol.

survivors and non-survivors. Logistic regression analysis was performed to identify the predictors of pleural effusion due to $\mathrm{PE}$, and odds ratio (OR) with $95 \%$ confidence interval (95\% CI) was calculated to assess the discriminatory power of these parameters. A Cox proportional hazards regression model was used to assess the impact of pleural effusion on survival and the results are presented as hazard ratio (HR) with $95 \%$ CI. Follow-up data of patients were analyzed with a time-to-event model by the Kaplan-Meier method and the log-rank test. All statistical analyses were performed using SPSS v21.0 (IBM, Chicago, IL, USA), and $\mathrm{P}<0.05$ was considered statistically significant.

\section{Results}

\section{Demographic and clinical characteristics of patients}

We screened 747 patients with APE by CTPA, and 112 were excluded because the cause of pleural effusion was not APE (Figure 1). Among the 635 patients with APE included in the analysis, the prevalence of pleural effusion was $57.01 \%(362 / 635)$.

Patients with pleural effusion were younger than those without effusion (control group) $(57.04 \pm 17.81 \mathrm{vs}$. $59.74 \pm 15.38$ years, $\mathrm{P}=0.041$ ). Additionally, the pleural effusion group had a lower frequency of unprovoked $\mathrm{PE}$ than controls $(18.0 \%$ vs. $27.5 \%, \mathrm{P}=0.004)$ and more clinical symptoms including dyspnea $(74.2 \%$ vs. $63.4 \%, \mathrm{P}=0.003)$, pleuritic chest pain $(39.3 \%$ vs. $28.9 \%, \mathrm{P}=0.007)$, hemoptysis (30.2\% vs. $21.2 \%, \mathrm{P}=0.011)$, and fever $(9.8 \%$ vs. $4.9 \%$,
$\mathrm{P}=0.024)$. The demographic and clinical information is summarized in Table 1.

\section{Laboratory and radiographic findings}

Patients with pleural effusion had higher WBC counts and serum levels of NT-pro BNP, troponin T, and CK-MB relative to controls, and more frequently exhibited pulmonary infarction in the radiographic examination $(26.0 \%$ vs. $19.0 \%$, $\mathrm{P}=0.038$ ) (Table 1). There were no significant differences between groups in terms of the location of pulmonary emboli, occurrence of deep vein thrombosis, and right ventricle dilation in the CT scan or ultrasonic cardiogram.

\section{Predictive factors for pleural effusion caused by APE}

To identify factors that could potentially contribute to the development of pleural effusion in APE, we performed a multivariate logistic regression analysis with age, immobilization, respiration rate, WBC count, and PLT count as candidate predictive factors based on their clinical significance and the results of the univariate analysis (all $\mathrm{P}<0.05)$. We found that immobilization $(\mathrm{OR}=1.575$; 95\% CI: $1.022-2.429, \mathrm{P}=0.04)$ and WBC count (OR $=1.056$; 95\% CI: 1.006-1.109, $\mathrm{P}=0.028$ ) were independent predictors of pleural effusion (Table 2).

\section{Pleural effusion and clinical outcome}

The in-hospital mortality rate was significantly higher in the pleural effusion group than in the control group $(9.9 \%$ vs. 
Table 1 Demographics and clinical characteristics of patients with pulmonary embolism group by pleural effusion

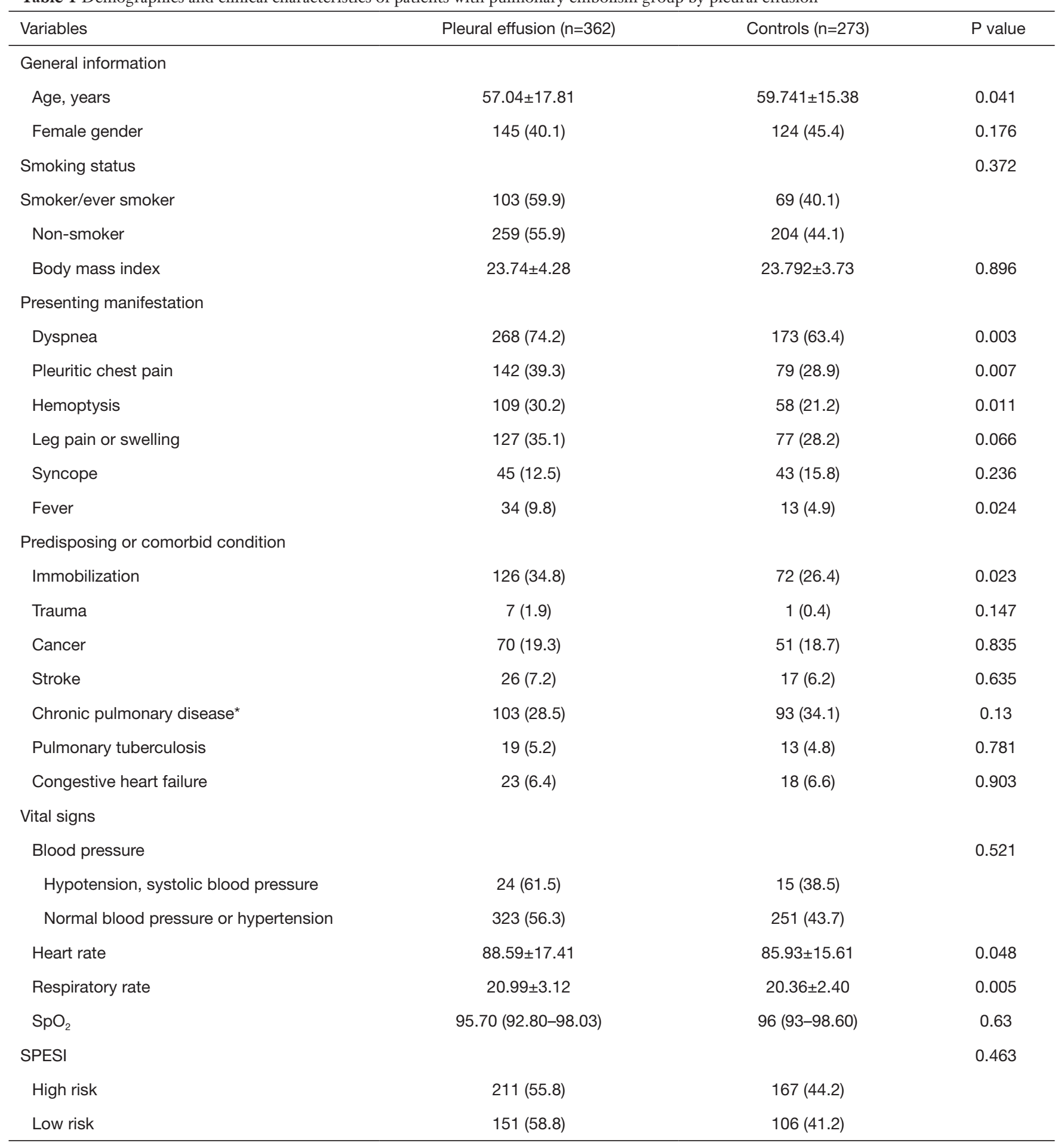

Table 1 (continued) 
Table 1 (continued)

\begin{tabular}{|c|c|c|c|}
\hline Variables & Pleural effusion ( $n=362$ ) & Controls $(n=273)$ & $P$ value \\
\hline High risk & $1(33.3)$ & $2(66.7)$ & \\
\hline Intermediate high & $77(61.1)$ & $49(38.9)$ & \\
\hline Intermediate low & $245(55.8)$ & $194(44.2)$ & \\
\hline \multicolumn{4}{|l|}{ Laboratory findings } \\
\hline WBC $\left(\times 10^{9} / L\right)$ & $8.82(6.17-11.74)$ & $7.32(5.30-9.63)$ & 0.00 \\
\hline PLT $\left(\times 10^{9} / \mathrm{L}\right)$ & $178.00(124.50-256.00)$ & 171.00 (129.50-231) & 0.083 \\
\hline NT-proBNP (pg/mL) & $793.00(152.00-2,709.00)$ & $387.00(104.75-1,880.75)$ & 0.029 \\
\hline \multicolumn{4}{|l|}{ Radiologic findings } \\
\hline $\begin{array}{l}\text { Location of the largest pulmonary } \\
\text { emboli (bilateral) }\end{array}$ & $188(51.9)$ & $140(51.7)$ & 0.946 \\
\hline Deep vein thrombosis & $131(57.7)$ & $105(54.4)$ & 0.496 \\
\hline $\begin{array}{l}\text { Right ventricle dilation on computed } \\
\text { tomography }\end{array}$ & $118(32.7)$ & $84(30.8)$ & 0.608 \\
\hline Pulmonary infarction & $94(26.0)$ & $52(19.0)$ & 0.038 \\
\hline \multicolumn{4}{|l|}{ Clinical outcome } \\
\hline Tracheal intubation & $9(15.0)$ & $3(7.1)$ & 0.35 \\
\hline Hospital bleeding & $23(22.1)$ & $11(10.4)$ & 0.021 \\
\hline
\end{tabular}

$4.8 \%, \mathrm{P}=0.015$ ) (Table 1). The presence of pleural effusion was associated with longer LOS $(19.99 \pm 24.41$ vs. $15.31 \pm 9.66$ days, $\mathrm{P}=0.006)$, more frequent hospital bleeding $(22.1 \%$ vs. $10.4 \%$, $\mathrm{P}=0.021)$, and a higher rate of respiratory failure $(20.4 \% v s$. $11.0 \%, P=0.001)$. However, there were no differences between groups in terms of tracheal intubation, mechanical ventilation, and systemic thrombolysis (all $\mathrm{P}<0.05)$.

\section{Predictors of mortality and survival analysis}

All patients were followed up until discharge from the hospital. In total, 49 patients died during hospitalization (in-hospital mortality rate of $7.72 \%$ ). We compared the data of survivors and non-survivors in order to identify potential predictors of in-hospital mortality in patients with APE. The prevalence of pleural effusion was significantly higher in non-survivors than in survivors $(73.5 \%$ vs. $55.8 \%$, $\mathrm{P}=0.016$ ) (Table 3). To determine whether the presence of pleural effusion or other indicators could predict inhospital mortality in patients with APE, we carried out Cox proportional hazards regression analyses (Table 4). The results of the univariate analysis indicated that pleural 
Table 2 Univariate and multivariate analysis for predictors of pleural effusion due to acute pulmonary embolism

\begin{tabular}{|c|c|c|c|c|c|c|}
\hline Variables & \multicolumn{3}{|c|}{ Univariate analysis } & \multicolumn{3}{|c|}{ Multivariate analysis } \\
\hline Age, years & 0.99 & $0.981-1.000$ & 0.046 & 0.99 & $0.978-1.002$ & 0.116 \\
\hline Immobilization & 1.49 & $1.055-2.105$ & 0.023 & 1.575 & $1.022-2.429$ & 0.04 \\
\hline Heart rate & 1.01 & $1.000-1.020$ & 0.052 & & & \\
\hline WBC $\left(\times 10^{9} / L\right)$ & 1.088 & $1.044-1.134$ & $<0.001$ & 1.056 & $1.006-1.109$ & 0.028 \\
\hline PLT $\left(\times 10^{9} / \mathrm{L}\right)$ & 1.002 & $1.001-1.004$ & 0.008 & 1.002 & $1.000-1.004$ & 0.099 \\
\hline NT-proBNP (pg/mL) & 1.000 & $1.000-1.000$ & 0.066 & & & \\
\hline Troponin T (ng/L) & 1.001 & $1.000-1.002$ & 0.082 & 1.001 & $1.000-1.002$ & 0.084 \\
\hline
\end{tabular}

Table 3 Demographics and clinical characteristics of patients with pulmonary embolism group by mortality

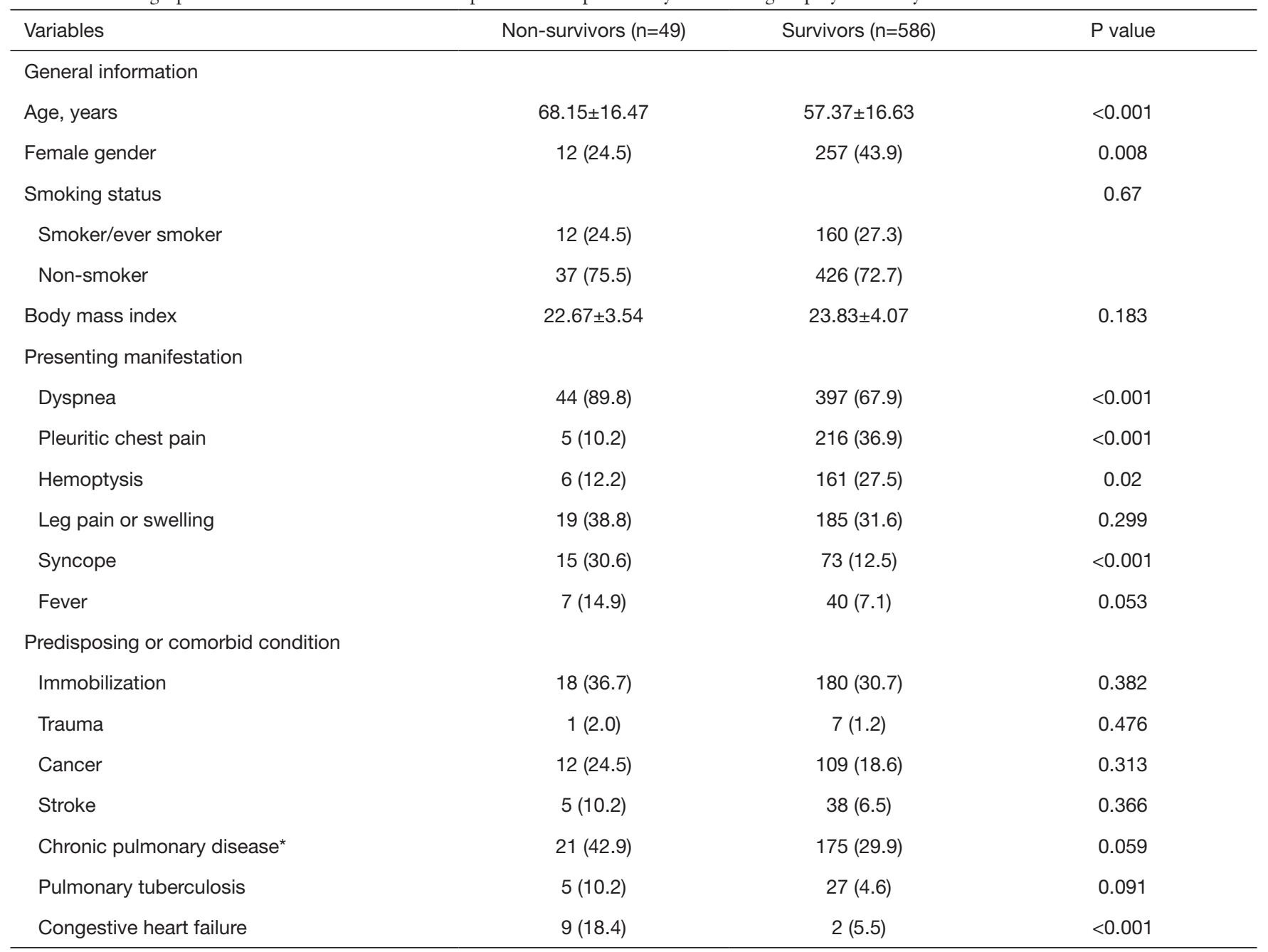

Table 3 (continued) 
Table 3 (continued)

\begin{tabular}{|c|c|c|c|}
\hline Variables & Non-survivors $(\mathrm{n}=49)$ & Survivors $(n=586)$ & $P$ value \\
\hline \multicolumn{4}{|l|}{ Vital signs } \\
\hline \multicolumn{4}{|l|}{ Blood pressure } \\
\hline Hypotension, systolic blood pressure & $6(12.8)$ & $33(5.8)$ & 0.061 \\
\hline Normal blood pressure or hypertension & $41(87.2)$ & $533(94.2)$ & 0.061 \\
\hline Respiratory rate & $21.45 \pm 4.45$ & $20.66 \pm 2.66$ & 0.236 \\
\hline $\mathrm{SpO}_{2}$ & $92.33 \pm 5.71$ & $94.75 \pm 5.57$ & 0.047 \\
\hline SPESI & & & $<0.001$ \\
\hline High risk & $41(83.7)$ & $337(57.5)$ & \\
\hline WBC $\left(\times 10^{9} / L\right)$ & $10.68(7.42-12.86)$ & $7.84(5.64-10.75)$ & $<0.001$ \\
\hline $\operatorname{PLT}\left(\times 10^{9} / \mathrm{L}\right)$ & 115 [78-190] & 177 [132-243] & $<0.001$ \\
\hline NT-proBNP (pg/mL) & $2800(889.25-8,085.5)$ & $425(106.5-2,163.5)$ & $<0.001$ \\
\hline Troponin T (ng/L) & $69.45(33.45-269.95)$ & $16.3(7.30-38.00)$ & $<0.001$ \\
\hline CK-MB (ng/mL) & $4.51(1.97-13.99)$ & $1.55(0.90-3.32)$ & $<0.001$ \\
\hline \multicolumn{4}{|l|}{ Radiologic findings } \\
\hline Pleural effusion & $36(73.5)$ & $327(55.8)$ & 0.016 \\
\hline Small pleural effusion & $35(97.2)$ & $320(97.9)$ & 0.805 \\
\hline Pulmonary infarction & $9(18.8)$ & $137(23.4)$ & 0.464 \\
\hline \multicolumn{4}{|l|}{ Clinical outcome } \\
\hline Respiratory failure & $24[49]$ & $80(13.7)$ & $<0.001$ \\
\hline Systemic thrombolysis & $0(0)$ & $1(0.3)$ & 1 \\
\hline Length of hospital stay, days & $18.76 \pm 21.40$ & $17.90 \pm 19.57$ & 0.810 \\
\hline Mechanical ventilation & $9(18.4)$ & $12(2.0)$ & $<0.001$ \\
\hline Tracheal intubation & $7(50.0)$ & $5(5.7)$ & $<0.001$ \\
\hline Hospital bleeding & $7(28.0)$ & $27(14.6)$ & 0.142 \\
\hline
\end{tabular}


Table 4 Univariate and multivariate Cox-regression analysis for predictors of in-hospital mortality

\begin{tabular}{|c|c|c|c|c|c|c|}
\hline Variables & \multicolumn{3}{|c|}{ Univariate analysis } & \multicolumn{3}{|c|}{ Multivariate analysis } \\
\hline Sex & 0.498 & $0.258-0.960$ & 0.037 & 0.492 & $0.179-1.352$ & 0.169 \\
\hline Congestive heart failure & 3.575 & $1.736-7.406$ & 0.001 & 1.552 & $0.455-5.295$ & 0.483 \\
\hline $\mathrm{SpO}_{2}$ & 0.946 & $0.899-0.996$ & 0.035 & 0.983 & $0.914-1.058$ & 0.647 \\
\hline SPESI & 2.190 & $1.638-2.927$ & $<0.001$ & 1.763 & $0.987-3.152$ & 0.056 \\
\hline WBC $\left(\times 10^{9} / \mathrm{L}\right)$ & 1.013 & $0.996-1.031$ & 0.126 & & & \\
\hline PLT $\left(\times 10^{9} / \mathrm{L}\right)$ & 0.994 & $0.990-0.998$ & 0.002 & 0.998 & $0.992-1.004$ & 0.591 \\
\hline CK-MB (ng/mL) & 1.000 & $0.997-1.003$ & 0.928 & & & \\
\hline Pleural effusion & 1.775 & $0.930-3.354$ & 0.077 & & & \\
\hline
\end{tabular}

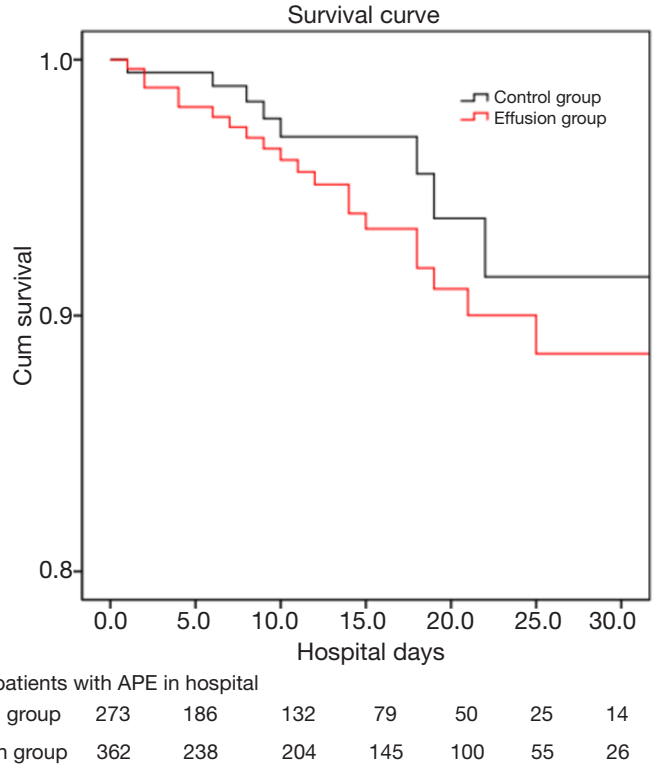

Figure 2 Kaplan-Meier curves of overall survival in patients with APE. The event was defined as in-hospital mortality, and patients were divided into effusion and control groups according to the presence of pleural effusion. The $\mathrm{P}$ value of the log-rank test was 0.174 .

effusion was a potential predictor $(\mathrm{HR}=2.21$; $95 \% \mathrm{CI}$ : $1.15-4.25, \mathrm{P}=0.018)$, but this was not confirmed in the multivariate analysis $(\mathrm{HR}=1.70,95 \% \mathrm{CI}: 0.73-3.92$,
$\mathrm{P}=0.216)$.

The Kaplan-Meier survival analysis revealed a difference in in-hospital mortality between the pleural effusion and non-pleural effusion groups; however, the log-rank analysis showed that the difference was not statistically significant $(\mathrm{P}=0.174)$ (Figure 2).

\section{Discussion}

The prevalence of pleural effusion and its relationship to clinical outcome in patients with APE is known. This was investigated in the present study and our results showed that pleural effusion was present in $57.01 \%$ of patients of APE, and was associated with higher in-hospital mortality, longer LOS, and higher rate of respiratory failure, although the Cox proportional hazards regression analysis did not support pleural effusion as an independent predictor of inhospital mortality in patients with APE.

The prevalence of pleural effusion has been reported as $16.32-61 \%(8,10,12,17,18) ; 2$ studies of Chinese patients with APE reported prevalence rates of $19.9 \%$ and $23.2 \%$ $(9,11)$. The prevalence in our study $(57.01 \%)$ suggests that pleural effusion is a common issue in patients with APE and merits greater attention from clinicians. Based on a retrospective analysis of more than 3,000 consecutive thoracentesis, PE was the cause of pleural effusion in just $1.6 \%$ of cases (19). Pleural effusion in APE is typically 
mild and bilateral, and most cases are not suitable for thoracentesis, making it more difficult to diagnose (20). The actual prevalence of pleural effusions due to APE may be different to calculate and the key-point is that physicians may neglect the differential diagnosis of undiagnosed pleural effusion regarding on APE, and missed the diagnosis of APE, which should pay more attention in clinical activities.

We carried out a multivariate logistic regression analysis to investigate potential indicators of pleural effusion caused by APE and found that immobilization and WBC were independent predictors. Patients with PE show an enhanced inflammatory response (21); WBC count, which is considered a marker of inflammation and hypercoagulability, was increased in patients with APE and was an independent predictor of short-term mortality (22). The increased WBC count in APE suggests that during the inflammatory response, inflammatory mediators released by pulmonary thrombi increase capillary permeability, which can lead to (although not required for) the development of pleural effusion in APE patients.

In our study, patients with pleural effusion had a higher in-hospital mortality rate than controls $(9.9 \%$ vs. $4.8 \%$, $\mathrm{P}=0.015$ ). A higher 30 -day all-cause mortality rate was previously reported in APE patients with pleural effusion compared to those without pleural effusion $(23 \% v s$. $9 \%, \mathrm{P}<0.001)(23)$. Pleural effusion was found to be an independent risk factor for poor prognosis in patients with APE, as its presence was correlated with higher mortality $(11,12)$. However, our Cox proportional hazards regression analysis showed that pleural effusion was not an independent predictor of in-hospital mortality in patients with APE ( $\mathrm{HR}=1.70$; 95\% CI: $0.73-3.92, \mathrm{P}=0.216$ ); this is consistent with a previous study demonstrating that pleural effusion did not predict short-term outcome in patients with APE (10). Thus, the impact of pleural effusion on the short-term mortality of patients with APE is complex and requires further investigation. On the other hand, given that many factors contribute to mortality in patients with APE, the effect of effusion should not be overstated.

In this study, NT-proBNP-a widely used cardiac biomarker for risk stratification in APE-was elevated in APE patients with pleural effusion relative to controls. Several studies have demonstrated that abnormal NTproBNP level is an indicator of right ventricular dysfunction, which is associated with poor outcome (24). APE patients who died in the first 30 days of hospitalization had significantly higher levels of NT-proBNP than those with longer survival times (25). For a full prognostic evaluation of patients with APE, pleural effusion must be considered along with other clinical data. In our analysis, mean LOS in patients with APE was longer than previously reported (26). This may be explained by the extreme values of LOS in a subset of our cohort, which may have skewed the results; alternatively, as China is a developing country, hospitalized patients have high expectations for treatment, resulting in a relatively long LOS.

Our study had 2 major limitations. Firstly, because of the retrospective single-center cohort design some data may have been missed, which could undermine the accuracy of the findings. Secondly, because of the limited follow-up time, there were no data on long-term clinical outcome of patients with APE; therefore, additional studies are needed to clarify whether this is affected by the presence of pleural effusion.

In conclusion, the results of this study demonstrate that pleural effusion is highly prevalent in patients with APE and may be associated with mortality, although it does not predict in-hospital mortality. These findings can guide the management of patients with APE by identifying those who might benefit from specific types of intervention, thereby improving their clinical outcome.

\section{Acknowledgments}

Funding: This work was supported by grants from Sichuan Key Research and Development Program (2019YJ0152, 2020YFS0147); the $1 \bullet 3 \bullet 5$ Project for Disciplines of Excellence, West China Hospital, Sichuan University (2019HXFH042); and National Key Research and Development Program (2016YFC1304202, 2016YFC1304500) and The funders had no role in study design, data collection and analysis, decision to publish, or preparation of the manuscript.

\section{Footnote}

Reporting Checklist: The authors have completed the STROBE reporting checklist. Available at http://dx.doi. org/10.21037/jtd-20-2552

Data Sharing Statement: Available at http://dx.doi. org/10.21037/jtd-20-2552

Peer Review File: Available at http://dx.doi.org/10.21037/jtd20-2552 
Conflicts of Interest: All authors have completed the ICMJE uniform disclosure form (available at http://dx.doi. org/10.21037/jtd-20-2552). The authors have no conflicts of interest to declare.

Etbical Statement: The authors are accountable for all aspects of the work in ensuring that questions related to the accuracy or integrity of any part of the work are appropriately investigated and resolved. The study was conducted in accordance with the Declaration of Helsinki (as revised in 2013). This study was approved by the Institutional Review Board of the West China Hospital of Sichuan University (WCH 2017-351). Individual consent for this retrospective analysis was waived.

Open Access Statement: This is an Open Access article distributed in accordance with the Creative Commons Attribution-NonCommercial-NoDerivs 4.0 International License (CC BY-NC-ND 4.0), which permits the noncommercial replication and distribution of the article with the strict proviso that no changes or edits are made and the original work is properly cited (including links to both the formal publication through the relevant DOI and the license). See: https://creativecommons.org/licenses/by-nc-nd/4.0/.

\section{References}

1. Tapson VF. Acute pulmonary embolism. N Engl J Med 2008;358:1037-52.

2. Hepburn-Brown M, Darvall J, Hammerschlag G. Acute pulmonary embolism: a concise review of diagnosis and management. Intern Med J 2019;49:15-27.

3. Lehnert P, Lange T, Møller CH, et al. Acute Pulmonary Embolism in a National Danish Cohort: Increasing Incidence and Decreasing Mortality. Thromb Haemost 2018;118:539-46.

4. Andersson T, Söderberg S. Incidence of acute pulmonary embolism, related comorbidities and survival; analysis of a Swedish national cohort. BMC Cardiovasc Disord 2017;17:155.

5. Rivera-Lebron B, McDaniel M, Ahrar K, et al. Diagnosis, Treatment and Follow Up of Acute Pulmonary Embolism: Consensus Practice from the PERT Consortium. Clin Appl Thromb Hemost 2019;25:1076029619853037.

6. Goldhaber SZ, Visani L, De Rosa M. Acute pulmonary embolism: clinical outcomes in the International Cooperative Pulmonary Embolism Registry (ICOPER). Lancet 1999;353:1386-9.
7. Shiraev TP, Omari A, Rushworth RL. Trends in pulmonary embolism morbidity and mortality in Australia. Thromb Res 2013;132:19-25.

8. Porcel JM, Madroñero AB, Pardina M, et al. Analysis of pleural effusions in acute pulmonary embolism: radiological and pleural fluid data from 230 patients. Respirology 2007;12:234-9.

9. Liu M, Cui A, Zhai ZG, et al. Incidence of pleural effusion in patients with pulmonary embolism. Chin Med J (Engl) 2015;128:1032-6.

10. Choi SH, Cha SI, Shin KM, et al. Clinical Relevance of Pleural Effusion in Patients with Pulmonary Embolism. Respiration 2017;93:271-8.

11. Zhou $X$, Zhang Z, Zhai Z, et al. Pleural effusions as a predictive parameter for poor prognosis for patients with acute pulmonary thromboembolism. J Thromb Thrombolysis 2016;42:432-40.

12. Olgun Yıldızeli Ş, Kasapoğlu US, Arıkan H, et al. Pleural effusion as an indicator of short term mortality in acute pulmonary embolism. Tuberk Toraks 2018;66:185-96.

13. Elias A, Mallett S, Daoud-Elias M, et al. Prognostic models in acute pulmonary embolism: a systematic review and meta-analysis. BMJ Open 2016;6:e010324.

14. Konstantinides SV, Meyer G, Becattini C, et al. 2019 ESC Guidelines for the diagnosis and management of acute pulmonary embolism developed in collaboration with the European Respiratory Society (ERS). Eur Heart J 2020;41:543-603

15. Saguil A, Wyrick K, Hallgren J. Diagnostic Approach to Pleural Effusion. Am Fam Physician 2014;90:99-104.

16. Jany B, Welte T. Pleural Effusion in Adults-Etiology, Diagnosis, and Treatment. Dtsch Arztebl Int 2019;116:377-86.

17. Yap E, Anderson G, Donald J, et al. Pleural effusion in patients with pulmonary embolism. Respirology 2008;13:832-6.

18. Agarwal R, Singh N, Gupta D. Pleural effusions associated with pulmonary thromboembolism: A systematic review. Indian J Chest Dis Allied Sci 2009;51:159-64.

19. Porcel JM, Esquerda A, Vives M, et al. Etiology of pleural effusions: analysis of more than 3,000 consecutive thoracenteses. Arch Bronconeumol 2014;50:161-5.

20. Panjwani A, Zaid T, Alawi S, et al. Pleural effusion in acute pulmonary embolism in Bahrain: Radiological and pleural fluid characteristics. Lung India 2019;36:112-7.

21. Alonso-Martínez JL, Anniccherico-Sánchez FJ, UrbietaEchezarreta MA, Pérez-Ricarte S. Inflammation in pulmonary embolism. Eur J Intern Med 
2013;24 Suppp 1:e237-8.

22. Venetz C, Labarère J, Jiménez D, et al. White blood cell count and mortality in patients with acute pulmonary embolism. Am J Hematol 2013;88:677-81.

23. Kiris T, Yazıc1 S, Koc A, et al. Prognostic impact of pleural effusion in acute pulmonary embolism. Acta Radiol 2017;58:816-24.

24. Goldhaber SZ. Thrombolysis in pulmonary embolism: a debatable indication. Thromb Haemost 2001;86:444-51.

Cite this article as: Zhang J, Zhou H, Aili A, Wang M, Shen Y, Yi Q. Prevalence and clinical significance of pleural effusion in patients with acute pulmonary embolism: a retrospective study. J Thorac Dis 2021;13(2):541-551. doi: 10.21037/jtd-20-2552
25. Lankeit M, Jiménez D, Kostrubiec M, et al. Validation of $\mathrm{N}$-terminal pro-brain natriuretic peptide cut-off values for risk stratification of pulmonary embolism. Eur Respir J 2014;43:1669-77.

26. Paczyńska M, Kurnicka K, Lichodziejewska B, et al. Acute pulmonary embolism treatment with rivaroxaban results in a shorter duration of hospitalisation compared to standard therapy: an academic centre experience. Kardiol Pol 2016;74:650-6. 